\title{
Clinical and polygraphic evolution of sleep- related breathing disorders in adolescents
}

\author{
A. Sánchez-Armengol*, A. Ruiz-García*, C. Carmona-Bernal*, \\ G. Botebol-Benhamou" ${ }^{\#}$, E. García-Díaz", J. Polo-Padillo ${ }^{+}$, \\ J.L. López-Campos* and F. Capote*
}

ABSTRACT: It has been suggested that sleep-related breathing disorders (SRBD) involve a continuum that develops over the course of life. If modifiable factors could be identified, the progression of SRBD could perhaps be addressed early in life. Although some studies have looked at the evolution of SRBD in pre-pubertal children, very few studies obtained data in adolescents.

Anthropometric, clinical and polygraphic variables were collected during a 4-yr follow-up study among 148 normal adolescents after initial cross-sectional analysis.

From a total of 267 adolescents studied at baseline (mean \pm SD age 14.3 $\pm 2.1 \mathrm{yrs}$ ), 148 (55.4\%) were followed up for 4 yrs. During follow-up, there were no significant changes in snoring and polygraphic parameters. However, a tendency toward weight gain with centrally distributed fat was observed. Habitual snorers had a significantly higher body mass index and more centrally distributed fat than nonsnorers. Males had a higher snoring prevalence and a higher number of respiratory events than females. Snoring at baseline, male sex and poor academic performance were significant predictors of snoring at follow-up.

Snoring tends to persist during adolescence and male sex acts as a risk factor. A relationship between snoring and academic performance was observed. These findings may have implications for long-term management of sleep-related breathing disorders.

KEYWORDS: Adolescence, follow-up, obesity, sex, sleep-related breathing disorders

I $\mathrm{t}$ has been suggested that sleep-related breathing disorders (SRBD) in childhood may be a risk factor for later development of adult sleep apnoea [1]. Several factors may play a role in linking childhood SRBD to the adult form of obstructive sleep apnoea, including complex genetic factors influencing upper airway morphology, uncorrected upper airway obstruction and obesity $[2,3]$. In this context, preventative strategies identifying and acting on modifiable risk factors may be of paramount importance for preventing and slowing the progression of SRBD. This may have major clinical implications in the light of the current evidence linking sleep apnoea/hypopnoea syndrome (SAHS) with traffic accidents [4], increased cardiovascular risk [5] and overall mortality [6].

The natural history of snoring and SRBD in childhood and adolescence remains controversial. Recent research has reported that SRBD may be associated with behavioural and cognitive dysfunction $[7,8]$. In contrast, other studies have suggested that childhood SRBD has a benign course in most cases. However, previous studies were limited to samples of pre-pubertal children, and changes during adolescence were not addressed $[9,10]$.

Adolescence may be crucial in the development of SRBD because hormonal changes during this period lead to anthropometric changes and muscle development that affects the entire organism, including the upper airway [11].

The general features of SRBD in the adolescent age group have been reported previously [12-15]. A cross-sectional study was carried out by the present authors between 1997 and 2000 in a population of 267 adolescents ranging 11-19 yrs of age. To shed more light on the natural history of SRBD during adolescence, the original population was prospectively followed up between 2002
AFFILIATIONS

${ }^{*}$ Medical-Surgical Unit of Respiratory Diseases

Depts of ${ }^{\#}$ Neurology and Clinical Neurophysiology, and

"Critical Care Medicine, Virgen del Rocio University Hospital, and ${ }^{+}$Dept of Statistics, Seville University, Seville, Spain.

CORRESPONDENCE

A. Sánchez-Armengol

Urb. Ciudad Expo

c/La Pinta

$58-2^{\circ} \mathrm{B}$

Mairena del Aljarafe 41927 Seville

Spain

Fax: 34955012191

E-mail: m.sanchez.armengol.sspa@ juntadeandalucia.es

Received:

October 112007

Accepted after revision:

June 032008

SUPPORT STATEMENT

This study was supported by the Programa de Intensification la Actividad health institute Carlos III (Madrid, Spain) and by a grant from the Fundacion de la Asociacion de Neumólogs del sur (Seville, Spain).

STATEMENT OF INTEREST

None declared. 
and 2004. In the present study, anthropometric, clinical and polygraphic variables were collected from 148 normal adolescents during a 4-yr follow-up period from the initial baseline assessment.

\section{METHODS \\ Study design}

The present study is the second prospective phase of a crosssectional study carried out by the current authors between 1997 and 2000 in a population of 267 adolescents ranging 1119 yrs of age. The study group was prospectively followed up between 2002 and 2004. The Institutional Review Board and Local Education Authorities (Seville, Spain) approved the study protocol. Adolescents gave written informed consent along with the written informed consent of their parent or legal guardian. Adolescents participating in the original crosssectional study were contacted after a 4-yr follow-up period. Families were initially invited to participate by letter. After 1 month, each potential participant was contacted by telephone and the study protocol was explained in more detail.

\section{Questionnaire}

A previously reported questionnaire [12-15] (see online supplementary data) was used in the follow-up study. The questionnaire was completed by a technician, and data were provided by the subject and their parents. Questions were answered at the adolescent's home, on the same night as the polygraphic recording was taken. Snorers answered "sometimes" or "often" to the question on snoring, while nonsnorers answered "never" or "rarely". Subjects who snored often were considered habitual snorers. Academic performances were classified as poor, average or good.

Height and weight were measured at baseline and upon completion of follow-up to calculate the body mass index $\left(\mathrm{BMI} ; \mathrm{kg} \cdot \mathrm{m}^{-2}\right)$. Neck, waist and hip circumferences were measured in all subjects. Waist-to-hip ratio (WHR) and neckto-height ratio (neck circumference divided by height $\mathrm{cm}$ ) were calculated [12]. The relationship between BMI and WHR values at baseline and follow-up (BMI2/BMI1 and WHR2/ WHR1 ratios, respectively) were also determined. The BMI zscore was defined as the deviation of the value of BMI for an individual from the mean value of the reference population divided by the SD for the reference population [16, 17].

\section{Respiratory polygraphy}

The overnight home polygraphy was performed using a portable ambulatory device (Apnoescreen II; Erich Jaeger $\mathrm{GmbH}$, Wuerzburg, Germany) with continuous monitoring of oronasal airflow (thermistor), chest and abdominal respiratory movements (thoracic and abdominal belts), arterial oxygen saturation $\left(\mathrm{S}_{\mathrm{a}}, \mathrm{O}_{2}\right.$; digital pulse oximetry), heart rate (finger probe), electrocardiography, body position (mercury sensor) and actigraphy (wristband with activity sensor) [12, 15]. The specific program for the analysis of the recordings was improved in the second phase to enable the recordings to be reproduced in real time. The recordings obtained in both phases were analysed manually with this new program. The following parameters were assessed: 1) apnoea, defined as an absence of oronasal airflow lasting $\geqslant 5 \mathrm{~s}$ [18]; 2) hypopnoea, defined as a reduction of oronasal airflow to $\geqslant 50 \%$ of the preceding breathing amplitude and a duration of $\geqslant 5 \mathrm{~s}$ with a reduction in the oxygen saturation; 3 ) desaturation, defined as a drop $\geqslant 4 \%$ in $\mathrm{Sa}_{1} \mathrm{O}_{2}$; and 4) cardiac event, defined as a change in cardiac frequency of $\geqslant 10$ beats $\cdot \mathrm{min}^{-1}$ over $\geqslant 10 \mathrm{~s}$ associated with apnoea, hypopnoea or desaturation.

The variables analysed were: total recording time (TRT); TRT in the supine position; baseline $\mathrm{Sa}_{1} \mathrm{O}_{2}$ obtained from the automatic analysis during the first minutes of recording; $\mathrm{Sa}_{1} \mathrm{O}_{2}$ nadir (lowest value recorded during TRT); percentage of TRT with $\mathrm{Sa}_{1} \mathrm{O}_{2}<90 \%$; desaturation index: the number of oxygen desaturation events per hour in the manual analysis; respiratory disturbance index (RDI): the number of apnoeas plus hypopnoeas per hour; and RDI in the supine position (RDIsupine).

\section{Statistical analysis}

The results are expressed as mean $\pm \mathrm{SD}$ or as percentages. To compare independent qualitative variables, the Chi-squared test and the McNemar test were employed to analyse the trend in the shift of the distribution of these variables. To compare continuous quantitative variables, a paired and unpaired t-test was used for independent samples or related samples respectively, depending on the case. The Levene test was used to assess the equality of variances, adjusting the p-value of the latter if they proved to be unequal. Variables that were significantly associated with snoring in the bivariate analysis were included in the multiple logistic regression model, and the odds ratio $(\mathrm{OR})$ and confidence interval $(\mathrm{CI})$ were estimated for each variable, to act as risk factors for the dependent variable "snoring". In addition, a binary logistic regression analysis was performed with the presence of $\geqslant 5$ RDI (obtained in the polygraphy at follow-up) as the dependent variable. Baseline anthropometric, clinical and polygraphic variables were entered into the model as potential predictors. A p-value $<0.05$ was considered statistically significant.

\section{RESULTS}

From a total of 267 adolescents studied at baseline, 204 were contacted after a 4 -yr follow-up period. The remaining 63 subjects were lost to follow-up. In total, 148 individuals $(72.5 \%$ of the subjects contacted, $55.4 \%$ of the initial study cohort) agreed to participate in the second part of the study. The final sample consisted of 76 females (51.4\%) and 72 males $(48.6 \%)$, with a mean \pm SD (range) age of $18.5 \pm 2.3(14-24)$ yrs.

As can be seen in table 1, there were no significant differences on baseline anthropometric, clinical or polygraphic parameters between completers and those who were lost to follow-up. A tendency toward weight gain with centrally distributed fat was observed in the 148 study participants, especially in males (table 2). At long-term follow-up, males presented with higher values than females in all the anthropometric parameters evaluated (table 3)

Of the 148 individuals included in the study, three subjects were unable to answer to the question about snoring at the follow-up assessment. In total, 29 subjects who answered sometimes $(n=11,7.4 \%)$ or often $(n=18,12.1 \%)$ to the question about snoring were classified as snorers at follow-up. The nonsnorer group included 116 subjects who answered never $(n=99,66.8 \%)$ or rarely $(n=17,11.4 \%)$. The percentage of snorers observed at follow-up (19.6\%) was lower than that 


\begin{tabular}{lccc} 
TABLE 1 & $\begin{array}{l}\text { Baseline characteristics of subjects who did or } \\
\text { did not complete the follow-up study }\end{array}$ \\
& Included & Not included & p-value \\
\hline Subjects n & 148 & 119 & \\
Males & $72(48.6)$ & $48(40.3)$ & NS \\
Females & $76(51.4)$ & $71(59.6)$ & NS \\
Age yrs & $14.3 \pm 2.1$ & $14.7 \pm 2.1$ & NS \\
Social status & & & \\
$\quad$ Manual work & $80(54.1)$ & $79(66.3)$ & NS \\
$\quad$ Nonmanual work & $68(45.9)$ & $40(33.6)$ & \\
BMI kg $\mathbf{m}^{-2}$ & $21.6 \pm 3.6$ & $21.8 \pm 3.7$ & NS \\
Snorers & $42(28.3)$ & $41(34.4)$ & NS \\
RDI & $3.43 \pm 1.8$ & $2.5 \pm 1.8$ & NS \\
DI & $2.02 \pm 2.2$ & $1.6 \pm 2.1$ & NS \\
\hline
\end{tabular}

Data are presented as $\mathrm{n}(\%)$ or mean $\pm \mathrm{SD}$, unless otherwise stated. BMI: body mass index; RDI: respiratory disturbance index (number of apnoeas plus hypopnoeas per hour of recording); DI: desaturation index (number of desaturations per hour of recording); NS: nonsignificant.

observed at baseline $(27.6 \%)$. However, there was no significant trend over time according to the McNemar test (table 4). As shown in table 4, 17 subjects (eight females and nine males) classified as snorers at the initial assessment (answered sometimes or often for the question on snoring) were classified as nonsnorers at follow-up (answered never or rarely at follow-up). These subjects were classified as exsnorers. Although ex-snorers had not lost weight, the average BMI z-score had decreased significantly from baseline values. In others words, the BMI z-score had moved away from the general tendency to gain weight and show a more central fat distribution pattern, maintaining anthropometric values similar to those at baseline (table 5).

As can be seen in table 4, there were seven subjects (four females and three males) who answered never or rarely to the question on snoring at baseline, but sometimes or often at the end of follow-up (no snore 1 and snore 2 group). A tendency toward weight gain with centrally distributed fat was observed during

\begin{tabular}{|c|c|c|c|}
\hline \multirow[t]{2}{*}{ TABLE 2} & \multicolumn{3}{|c|}{$\begin{array}{l}\text { Changes in anthropometric measures during a } \\
4 \text {-yr follow-up in the overall cohort }{ }^{\#}\end{array}$} \\
\hline & Baseline & $\begin{array}{l}\text { Long-term } \\
\text { follow-up }\end{array}$ & p-value \\
\hline Age yrs & $14.3 \pm 2.1$ & $18.5 \pm 2.3$ & \\
\hline BMI $\mathbf{k g} \cdot \mathrm{m}^{-2}$ & $21.6 \pm 3.6$ & $22.6 \pm 3.8$ & $<0.001$ \\
\hline WHR & $0.79 \pm 0.08$ & $0.82 \pm 0.08$ & $<0.001$ \\
\hline NHR & $0.19 \pm 0.01$ & $0.2 \pm 0.02$ & 0.003 \\
\hline BMI2/BMI1 & & $105.13 \pm 14.49$ & \\
\hline WHR2/WHR1 & & $104.12 \pm 10.77$ & \\
\hline
\end{tabular}

Data are presented as mean $\pm S D$, unless otherwise stated. BMI: body mass index; WHR: waist-to-hip ratio; NHR: neck-to-height ratio; BMI2/BMl1: BMl at the end of follow-up/BMl at baseline; WHR2/WHR1: WHR at the end of follow-up/ WHR at baseline. ${ }^{*}: n=148$.
TABLE 3 Anthropometric measures stratified by sex at the end of follow-up

\begin{tabular}{lccc} 
& Females & Males & p-value \\
\hline Subjects $\mathbf{n}$ & 76 & 72 & \\
z-score BMI & $0.15 \pm 1.15$ & $0.25 \pm 1.07$ & NS \\
WHR & $0.77 \pm 0.06$ & $0.87 \pm 0.05$ & $<0.001$ \\
NHR & $0.19 \pm 0.01$ & $0.21 \pm 0.02$ & $<0.001$ \\
BMl2/BMI1 & $102.41 \pm 9.69$ & $108 \pm 17.87$ & 0.02 \\
WHR2/WHR1 & $103.24 \pm 9.77$ & $105.06 \pm 11.73$ & NS \\
\hline
\end{tabular}

Data are presented as mean $\pm S D$, unless otherwise stated. BMI: body mass index; z-score BMI: deviation of the value for an individual from the mean value of the reference population divided by the SD for the reference population; WHR: waist-to-hip ratio; NHR: neck-to-height ratio; $\mathrm{BMl} / \mathrm{BMl} 1$ : $\mathrm{BMl}$ at the end of follow-up/BMI at baseline; WHR2/WHR1: WHR at the end of follow-up/WHR at baseline; NS: nonsignificant.

follow-up (table 6). However, this difference failed to reach statistical significance, probably due to the small sample size.

Among the 18 subjects who were habitual snorers (snoring often) at long-term follow-up, there was a predominance of males (14 male versus four females; $p=0.01$ ), with 14 of them being classified as habitual snorers at baseline (table 4). No differences were found between the 18 habitual snorers and 99 nonsnorers with regard to the professional level of their parents (manual work: 55.5 versus 52.5\%; nonmanual work: 44.4 versus $47.4 \%$ ) or some habits in adolescence, such as alcohol consumption (44.4 and $37.3 \%$ of snorers and nonsnorers, respectively) or cigarette smoking (33.3 and $24.2 \%$ of snorers and nonsnorers, respectively).

Both at baseline and after follow-up, patients classified as habitual snorers $(n=18)$, had significantly higher $z$-score values for BMI, and more centrally distributed fat than nonsnorers (table 7). Table 7 also depicts symptoms related to SRBD in habitual snorers and nonsnorers at baseline and follow-up. There was no difference between the academic performances of habitual snorers compared with nonsnorers at baseline. However, at the end of the follow-up, good grades were achieved by $33.3 \%$ of habitual snorers compared with $57.5 \%$ of nonsnorers. Moreover, $16.6 \%$ of habitual snorers earned poor grades compared with $7.0 \%$ of nonsnorers $(p=0.005)$.

In the entire study cohort, data were collected by questionnaire at the end of follow-up on education level and working status. Data on these variables were collected retrospectively for subjects who were not yet studying. Results were as follows: manual work, $\mathrm{n}=10$; mean education level (compulsory secondary school, bachelor or nonuniversity degree), $n=88$; higher education level (university degree), $n=50$.

Table 8 presents the polygraphic changes in the entire study cohort at baseline and follow-up. Polygraphic results at followup stratified by sex are depicted in table 9 . A binary logistic regression analysis was performed with the presence of $\geqslant 5$ RDI (obtained in follow-up polygraphy) as the dependent variable. Male sex showed a slight but not significant association with $\geqslant 5$ RDI (95\% CI 0.149-1.017, $\mathrm{p}=0.054)$. No 


\begin{tabular}{ccccc} 
TABLE 4 & \multicolumn{3}{c}{$\begin{array}{l}\text { Changes in the prevalence of snoring during a } \\
\text { 4-yr follow-up }\end{array}$} \\
Baseline & \multicolumn{5}{c}{ Long-term follow-up } \\
\cline { 2 - 5 } & $\mathbf{N}$ & $\mathbf{R}$ & $\mathbf{S}$ & $\mathbf{0}$ \\
\hline $\mathbf{N}$ & 76 & 9 & 2 & 3 \\
$\mathbf{R}$ & 7 & 3 & 2 & 0 \\
$\mathbf{S}$ & 11 & 2 & 4 & 1 \\
$\mathbf{O}$ & 1 & 3 & 3 & 14 \\
\hline
\end{tabular}

Data are expressed as the number of subjects. Subjects (and/or their relatives) were asked: "Does he/she snore?" Responses were recorded as N (never), R (rarely: once per week or less), S (sometimes: twice per week), O (often: three or more times per week). Data were missing for four subjects at baseline and three subjects at follow-up. McNemar test: $p=0.084$.

other anthropometric, clinical and polygraphic variables were found to be significant predictors of $\geqslant 5$ RDI at follow-up.

The presence of snoring at baseline was a strong predictor of snoring at follow-up (OR 41.9, 95\% CI 8.7-200.8; p<0.001). Multiple logistic regression analysis identified male sex (OR $3.07,95 \%$ CI 1.22-7.68; $\mathrm{p}=0.01$ ) as a significant independent predictor of snoring at follow-up. In contrast, good academic performances were independently associated with a reduced risk of snoring at follow-up (OR 0.47, 95\% CI 0.28-0.78; $\mathrm{p}=0.004)$.

\section{DISCUSSION}

The evolution of snoring and the polygraphic findings after 4 yrs have tended toward stability, despite the fact that there was a significant tendency to gain weight and develop a pattern of more central body fat distribution. Adolescents who snored at baseline and no longer snored at long-term follow-up did not follow this trend and maintained stable anthropometric parameters. Habitual snorers had a higher BMI and a greater tendency toward central body fat distribution than nonsnorer

\begin{tabular}{lccc} 
TABLE 5 & $\begin{array}{l}\text { Changes in anthropometric measures during a } \\
\text { 4-yr follow-up in } 17\end{array}$ & ex-snorers \\
& Baseline & $\begin{array}{c}\text { Long-term } \\
\text { follow-up }\end{array}$ & p-value \\
& & $17.82 \pm 2.4$ & \\
\hline Age yrs & $13.94 \pm 2.13$ & $0.20 \pm 0.03$ & NS \\
NHR & $0.20 \pm 0.02$ & $0.07 \pm 0.72$ & 0.016 \\
z-score BMI & $0.68 \pm 1.2$ & $0.83 \pm 0.06$ & NS \\
WHR & $0.85 \pm 0.10$ & $98.59 \pm 14.35$ & \\
BMI2/BMl1 & & $98.06 \pm 12.06$ & \\
WHR2/WHR1 & & &
\end{tabular}

Data are presented as mean \pm SD, unless otherwise stated. NHR: neck-to-height ratio; $\mathrm{BMI}$ : body mass index; $\mathrm{z}$-score $\mathrm{BMI}$ : deviation of the value for an individual from the mean value of the reference population divided by the SD for the reference population; WHR: waist-to-hip ratio; $\mathrm{BMl} 2 / \mathrm{BMl}$ : $\mathrm{BMI}$ at the end of follow-up/BMI at baseline; WHR2/WHR1: WHR at the end of follow-up/WHR at baseline; Ns: nonsignificant.

\begin{tabular}{lccc} 
TABLE 6 & $\begin{array}{l}\text { Changes in anthropometric measures during a } \\
\text { 4-yr follow-up in the no snore 1 and snore 2 } \\
\text { groups }\end{array}$ \\
& Baseline & $\begin{array}{c}\text { Long-term } \\
\text { follow-up }\end{array}$ & p-value \\
\hline Age yrs & $16.14 \pm 2.5$ & $20.2 \pm 2.5$ & \\
BMI kg. m-2 & $21.4 \pm 4.3$ & $22.3 \pm 4.9$ & 0.09 \\
NHR & $0.19 \pm 0.01$ & $0.2 \pm 0.01$ & 0.18 \\
WHR & $0.76 \pm 0.05$ & $0.82 \pm 0.05$ & 0.06 \\
\hline
\end{tabular}

Data are presented as mean $\pm \mathrm{SD}$, unless otherwise stated. BMI: body mass index; NHR: neck-to-height ratio; WHR: waist-to-hip ratio. ${ }^{\#}: \mathrm{n}=7$.

subjects in both stages of the study. They also had poorer academic performance than the nonsnorers in the second phase. At baseline, snorers described symptoms that are common in SRBD of children [12]. At long-term follow-up, snorer adolescents had other symptoms, such as nocturnal awakenings and asthenia, with a pattern similar to SAHS in adults. In the present study, habitual smokers were predominantly male and, moreover, males experienced more respiratory events (apnoeas and hypopnoeas) during respiratory polygraphy than females, differences that were not observed in the previous phase.

An important strength of the present study is that it was prospective and carried out over a longer follow-up period compared with previous studies $[19,20]$. It is worth noting that short observation periods may often not be sufficient to assess the natural history of chronic disorders such as SRBD. Among a total of 267 adolescents studied at baseline, 204 were contacted after a 4-yr follow-up period. In total, 148 subjects (72.5\% of the subjects contacted, $55.4 \%$ of the initial study cohort) agreed to participate in the second phase of the study. The test-re-test reliability achieved in the present study $(55.4 \%)$ is close to the threshold values recommended for cohort studies [21]. Although loss to follow-up is problematic in most cohort studies and often leads to bias, in the current study, baseline anthropometric, clinical and polygraphic characteristics of subjects who did $(n=148)$ or did not $(n=119)$ complete the follow-up study were similar (table 1). Thus, a major bias related to test-re-test reliability is unlikely in the present study. The participation rate is similar to that reported previously in a population-based cohort study [9], and higher than those reported in previous follow-up [22] and cross-sectional studies [23]. This is an important strength of the present study because long time intervals have generally been negatively related to response rates [24].

The questionnaire was completed by a technician, and data were provided by the subjects and their parents. This methodology is in keeping with that used in adult patients with suspected SRBD, i.e. history collected by the physician from the patient and their partner. The presence of snoring was validated based on data provided by parents, since no partner is available during adolescence. This is an inherent shortcoming of studies conducted in this age range. It is believed that long-term data provided by the parents are more reliable 


\begin{tabular}{llcc}
\hline TABLE 7 & $\begin{array}{l}\text { Changes in anthropometric and clinical } \\
\text { parameters in habitual snorers and nonsnorers } \\
\text { during a 4-yr follow-up }\end{array}$ \\
& Nonsnorers & $\begin{array}{c}\text { Habitual } \\
\text { snorers }\end{array}$ & p-value \\
& & & \\
& & & \\
\hline & 99 & 18 & \\
Subjects n & & & 0.018 \\
Anthropometric variables & $0.19 \pm 0.01$ & $0.2 \pm 0.01$ & 0.08 \\
Baseline NHR & $0.2 \pm 0.01$ & $0.22 \pm 0.04$ & 0.08 \\
Long-term follow-up NHR & $0.2 \pm 0.95$ & $0.89 \pm 1.31$ & 0.04 \\
Baseline z-score BMI & $0.03 \pm 0.97$ & $0.91 \pm 1.61$ & 0.03 \\
Long-term follow-up z-score BMI & $0.78 \pm 0.08$ & $0.82 \pm 0.05$ & 0.022 \\
Baseline WHR & $0.81 \pm 0.08$ & $0.88 \pm 0.04$ & 0.000 \\
Long-term follow-up WHR & & & \\
Questionnaire & $0(0)$ & $1(5.5)$ & NS \\
Apnoeas & $18(18.1)$ & $5(27.7)$ & NS \\
Restless sleep & $28(28.2)$ & $10(55.5)$ & 0.03 \\
Awakenings at night & $6(6.0)$ & $2(11.1)$ & NS \\
Laboured breathing & $24(24.2)$ & $4(22.2)$ & NS \\
Daytime sleepiness & $24(24.2)$ & $9(50.0)$ & 0.04 \\
Asthenia & & & \\
\hline
\end{tabular}

Data are presented as mean \pm SD or $n(\%)$, unless otherwise stated. NHR: neckto-height ratio; BMI: body mass index; Z-score BMl: deviation of the value for an individual from the mean value of the reference population divided by the SD for the reference population; WHR: waist-to-hip ratio; NS: nonsignificant.

than those collected by a microphone during a single night for classifying subjects as either snorers or nonsnorers.

With regard to the methodology used for respiratory polygraphy, nasal cannula pressure recordings for nasal flow were not used at baseline. Therefore, this parameter was excluded from follow-up assessments for consistency with baseline evaluations. Oronasal airflow was monitored with a thermistor at baseline and at the end of the follow-up.

\begin{tabular}{lccc} 
TABLE 8 & \multicolumn{3}{c}{$\begin{array}{l}\text { Changes in polygraphic parameters during a 4-yr } \\
\text { follow-up }\end{array}$} \\
& Baseline & $\begin{array}{l}\text { Long-term } \\
\text { follow-up }\end{array}$ & p-value \\
& $512.88 \pm 74.5$ & $461.68 \pm 90.51$ & 0.000 \\
\hline TRT min & $86.07 \pm 9.31$ & $87.63 \pm 5.81$ & NS \\
${\text { Sa, } \mathbf{O}_{\mathbf{2}} \text { min }}_{\text {CT }}$ & $0.07 \pm 0.41$ & $0.07 \pm 0.39$ & NS \\
DI & $2.02 \pm 2.25$ & $2.46 \pm 2.62$ & NS \\
RDI & $3.43 \pm 1.88$ & $3.33 \pm 1.95$ & NS \\
RDIsupine & $4.3 \pm 3.27$ & $3.99 \pm 3.66$ & NS \\
Cardiac events & $26.2 \pm 14.04$ & $21.5 \pm 14.04$ & 0.002 \\
\hline
\end{tabular}

Data are presented as mean $\pm \mathrm{SD}$, unless otherwise stated. TRT: total recording time; $\mathrm{Sa}, \mathrm{O}_{2}$ : arterial oxygen saturation; CT90: percentage of TRT with $\mathrm{Sa}_{1} \mathrm{O}_{2}$ $<90 \%$; DI: desaturation index (number of desaturations per hour of recording); RDI: respiratory disturbance index (number of apnoeas plus hypopnoeas per hour of recording); RDlsupine: RDI in the supine position; cardiac events: change in cardiac frequency of $\geqslant 10$ beats $\cdot \mathrm{min}^{-1}$ over $\geqslant 10 \mathrm{~s}$ associated with apnoea, hypopnoea or desaturation; Ns: nonsignificant.

\begin{tabular}{|c|c|c|c|}
\hline \multirow[t]{2}{*}{ TABLE 9} & \multirow[b]{2}{*}{ Females } & ameters du & \multirow[b]{2}{*}{$\mathrm{p}$-value } \\
\hline & & Males & \\
\hline \multicolumn{4}{|l|}{ DI } \\
\hline Baseline & $1.54 \pm 2.10$ & $2.53 \pm 2.30$ & 0.007 \\
\hline Long-term follow-up & $2.07 \pm 2.52$ & $2.88 \pm 2.67$ & 0.06 \\
\hline \multicolumn{4}{|l|}{ RDI } \\
\hline Baseline & $3.21 \pm 1.90$ & $3.65 \pm 1.84$ & NS \\
\hline Long-term follow-up & $3.01 \pm 1.70$ & $3.67 \pm 2.14$ & 0.04 \\
\hline \multicolumn{4}{|l|}{ Supine RDI } \\
\hline Baseline & $3.83 \pm 2.75$ & $4.79 \pm 3.70$ & NS \\
\hline Long-term follow-up & $3.38 \pm 2.35$ & $4.63 \pm 4.59$ & 0.03 \\
\hline \multicolumn{4}{|l|}{ Cardiac events } \\
\hline Baseline & $23.95 \pm 15.01$ & $28.57 \pm 12.62$ & 0.04 \\
\hline Long-term follow-up & $20.54 \pm 11.15$ & $22.51 \pm 16.57$ & NS \\
\hline
\end{tabular}

Data are presented as mean $\pm \mathrm{SD}$, unless otherwise stated. DI: desaturation index (number of desaturations per hour of recording); RDI: respiratory disturbance index (number of apnoeas plus hypopnoeas per hour of recording); cardiac events: change in cardiac frequency $\geqslant 10$ beats $\cdot \mathrm{min}^{-1}$ during $\geqslant 10 \mathrm{~s}$, associated with apnoea, hypopnoea or desaturation; NS: nonsignificant.

It was found that $19.5 \%$ of the sample of adolescents snored at follow-up, with a prevalence of habitual snoring of $12.1 \%$. These rates were slightly higher than those reported previously in younger children $[25,26]$, but similar to those observed among adolescents [27] and lower than those reported in adults [28]. Thus, the prevalence of snorers in the current adolescent age group was intermediate between those observed in childhood and adulthood. This finding was expected given the age range of the study population.

The American Academy of Pediatrics [29] has argued that snoring in children tends to resolve in most cases, thereby presenting a fairly benign course. Two recent studies in children aged 9-13 yrs have demonstrated that a significant decrease occurred in the prevalence of habitual snorers by the end of the follow-up $[9,10]$. However, the current data (table 4) showed that snoring tends to persist during adolescence. It is thus posited that the significant increase in the upper airway diameter occurring at $\sim 10$ yrs of age (as a result of body growth and the reduction in the upper airway lymphoid tissue) may be counteracted by increased oropharyngeal muscle development mediated, in part, by hormonal influences, as well as by the tendency to develop central accumulation of fat with weight gain during adolescence. In the present study, snoring at baseline independently predicted snoring at follow-up (OR 41.9, 95\% CI 8.7-200.8; $<<0.001$ ). This result reinforced the idea that snoring during adolescence tends to persist in the absence of therapeutic intervention.

During adolescence, fat-free mass tends to increase and patterns of fat distribution change, especially in males [30], which is considered normal at this stage of life. An exaggeration of this tendency could contribute to the so-called epidemic of child obesity that is currently affecting children in all developed countries. A European cross-sectional, multicentre 
study [31] found as high a percentage of overweight and obese adolescents in Europe as those reported in studies involving children in the USA. All these studies compared crosssectional samples obtained in different years. The same initial series of subjects have been followed over 4 yrs and the same significant trend was detected, especially in males, toward gaining weight and developing a more central body fat distribution pattern (tables 2 and 3). Of interest is also the observation that habitual snorers had a significantly higher BMI and more centrally distributed fat than nonsnorers. In agreement with these results, several previous studies have shown that obesity is an important determinant of habitual snoring and SRBD in children and adolescents [9, 12, 32, 33]. A more central pattern of body fat distribution has been also associated with the presence of SRBD in adults, obese children and adolescents [34,35], as well as with metabolic or vascular complications in both adults [36] and children [37]. The subjects in the present study considered ex-snorers have moved away from the trend toward developing central obesity (tables 5 and 6). These data suggest that healthcare interventions aimed to prevent or reduce the prevalence of obesity in children and adolescents may also exert beneficial effects on SRBD-related symptoms.

There are data about the relationship between snoring and school performance, especially since the study of GozAL and POPE [38] who reported that children who habitually snored during childhood are more likely to exhibit poor academic performance, even years after the snoring had been resolved. In the present study, there was no difference in academic performance of habitual snorers and nonsnorers at baseline. However, a higher percentage of habitual snorers earned poor grades compared with nonsnorers at follow-up. This finding was further substantiated by the fact that poor academic performance was a significant predictor of snoring at followup in multiple logistic regression analysis.

The prevalence of SRBD is the same in children of both sexes $[12,39,40]$, and the differences between males and females that develop during puberty are usually attributed to sex hormones. In the first phase of the present study, there was no male predominance among the snorers [12], but when the population was divided by stage of pubertal development, sexrelated differences were observed among the post-pubertal adolescents, with a higher prevalence of snoring and more polygraphic disturbances in males [15]. In the current longitudinal study, a predominance of males among the habitual snorers (14 out of 18) was found at long-term follow-up. Moreover, in the multiple regression analysis, male sex was shown to have an OR of 3.07 for the dependent variable snoring. Thus, male sex seems to become a risk factor for the development of SRBD once a child reaches puberty. The males in the current study also presented higher RDI and RDIsupine in the polygraphic recording of the second phase (table 9), a circumstance that had not been observed 4 yrs previously, and which is a finding consistent with those described in epidemiological studies in adults [28].

In addition, binary logistic regression revealed that male sex had a slight but not significant association with $\geqslant 5$ RDI obtained at follow-up polygraphy. It should be noted, however, that respiratory polygraphic results at baseline and follow-up (table 8) were within the normal ranges for adolescents [41-44]. The present study showed no changes in polygraphic data during the follow-up, the only exception being a decrease in the number of cardiac events. This result is likely to be ascribed to the role of these events as markers of autonomic arousal in the youngest children [45].

In conclusion, it appears that habitual snoring tends to persist during adolescence if no intervention is undertaken to modify its natural history. This could be achieved, in part, by avoiding the tendency of adolescents to gain weight. There is a relationship between snoring and school performance. Besides, male sex becomes a risk factor for sleep-related breathing disorders in adolescence.

\section{REFERENCES}

1 McNamara F, Sullivan CE. The genesis of adult sleep apnoea in childhood. Thorax 2000; 55: 964-969.

2 Redline S, Kump K, Tishler PV, Browner I, Ferrette V. Gender differences in sleep disordered breathing in a community-based sample. Am J Respir Crit Care Med 1994; 149: 722-726.

3 Guilleminault C, Pelayo R. Sleep-disordered breathing in children. Ann Med 1998; 30: 350-356.

4 Teran-Santos J, Jimenez-Gomez A, Cordero-Guevara J. The association between sleep apnea and the risk of traffic accidents. Cooperative Group Burgos-Santander. N Engl J Med 1999; 340: 847-851.

5 Peppard PE, Young T, Palta M, Skatrud J. Prospective study of the association between sleep-disordered breathing and hypertension. N Engl J Med 2000; 342: 1378-1384.

6 Yaggi HK, Concato J, Kernan WN, Litchman JH, Brass LM, Mohsenin V. Obstructive sleep apnea as a risk factor for stroke and death. N Engl J Med 2005; 353: 2034-2041.

7 Kheirandish L, Gozal D. Neurocognitive dysfunction in children with sleep disorders. Dev Sci 2006; 9: 388-399.

8 Kotagal S. Childhood obstructive sleep apnoea. Serious neurobehavioural sequelae have prompted interest in diagnosis and management. BMJ 2005; 330: 978-979.

9 Urschitz MS, Guenther A, Eitner S, et al. Risk factors and natural history of habitual snoring. Chest 2004; 126: 790-800.

10 Anuntaseree W, Kuasirikul S, Suntornlohanakul S. Natural history of snoring and obstructive sleep apnea in Thai school-age children. Pediatr Pulmonol 2005; 39: 415-420.

11 Ronen O, Malhotra A, Pillar G. Influence of gender and age on upper-airway length during development. Pediatrics 2007; 120: 1028-1034.

12 Sanchez-Armengol A, Fuentes-Pradera MA, Capote-Gil F, et al. Sleep-related breathing disorders in adolescents aged 12 to 16 years: clinical and polygraphic findings. Chest 2001; 119: 1393-1400.

13 Sanchez-Armengol A, Rodriguez-Puras MJ, FuentesPradera MA, et al. Echocardiographic parameters in adolescents with sleep-related breathing disorders. Pediatr Pulmonol 2003; 36: 27-33.

14 Fuentes-Pradera MA, Botebol G, Sanchez-Armengol A, et al. Effect of snoring and obstructive respiratory events on sleep architecture in adolescents. Arch Pediatr Adolesc Med 2003; 157: 649-654. 
15 Fuentes-Pradera MA, Sanchez-Armengol A, Capote-Gil F, et al. Effects of sex on sleep-disordered breathing in adolescents. Eur Respir J 2004; 23: 250-254.

16 Sobradillo B, Aguirre A, Aresti U, et al. Curvas y tablas de crecimiento (estudio longitudinal y transversal). In: Fundación F. Orbegozo, ed. Patrones de crecimiento y desarrollo en España. Atlas de gráficas y tablas. Madrid, Ergón, 2004; pp. 145-168.

17 Serra-Majem L, Ribas Barba L, Aranceta Bartrina J, et al. Obesidad infantil y juvenil en España.Resultados del estudio enKid (1998-2000). [Childhood adolescent obesity in Spain. Results of the enKid study (1998-2000).]. Med Clin (Barc) 2003; 121: 725-732.

18 Sanchez-Armengol A, Capote-Gil F, Cano-Gomez S, Ayerbe-Garcia R, Delgado-Moreno F, Castillo-Gomez J. Polysomnographic studies in children with adenotonsillar hypertrophy and suspected obstructive sleep apnea. Pediatr Pulmonol 1996; 22: 101-105.

19 Marcus CL, Hamer A, Loughlin GM. Natural history of primary snoring in children. Pediatr Pulmonol 1998; 26: 6-11.

20 Ali NJ, Pitson D, Stradling JR. Natural history of snoring and related behaviour problems between the ages of 4 and 7 years. Arch Dis Child 1994; 71: 74-76.

21 Kristman V, Manno M, Coté P. Loss to follow-up in cohort studies: how much is too much? Eur J Epidemiol 2004; 19: 751-760.

22 Tasker C, Crosby JH, Stradling JR. Evidence for persistence of upper airway narrowing during sleep, 12 years after adenotonsillectomy. Arch Dis Child 2002; 86: 34-37.

23 Goodwin JL, Babar SI, Kaemingk KL, et al. Symptoms related to sleep-disordered breathing in white and Hispanic children: the Tucson Children's Assessment of Sleep Apnea Study. Chest 2003; 124: 196-203.

24 Corbo GM, Forastiere F, Agabiti N, et al. Snoring in 9- to 15-year-old children: risk factors and clinical relevance. Pediatrics 2001; 108: 1149-1154.

25 Anuntaseree W, Rookkapan K, Kuasirikul S, Thongsuksai P. Snoring and obstructive sleep apnea in Thai school-age children: prevalence and predisposing factors. Pediatr Pulmonol 2001; 32: 222-227.

26 Guilleminault C, Lee JH, Chan A. Pediatric obstructive sleep apnea syndrome. Arch Pediatr Adolesc Med 2005; 159: 775-785.

27 Hui DS, Chan JK, Ho AS, Choy DK, Lai CK, Leung RC. Prevalence of snoring and sleep-disordered breathing in a student population. Chest 1999; 116: 1530-1536.

28 Young T, Palta M, Dempsey J, Skatrud J, Weber S, Badr S. The occurrence of sleep-disordered breathing among middle-aged adults. N Engl J Med 1993; 328: 1230-1235.

29 Section on Pediatric Pulmonology, Subcommittee on Obstructive Obstructive Sleep Apnea Syndrome, American Academy of Pediatrics. Clinical practice guideline: diagnosis and management of childhood obstructive sleep apnea syndrome. Pediatrics 2002; 109: 704-712.
30 Daniels SR, Arnett DK, Eckel RH, et al. Overweight in children and adolescents. Pathophysiology, consequences, prevention and treatment. Circulation 2005; 111: 1999-2012.

31 Moreno LA, Mesana MI, Fleta J, et al. Overweight, obesity and fat composition in Spanish adolescents. The AVENA Study. Ann Nutr Metab 2005; 49: 71-76.

32 Redline S, Tishler PV, Schluchter M, Aylor J, Clark K, Graham G. Risk factors for sleep-disordered breathing in children. Association with obesity, race and respiratory problems. Am J Respir Crit Care Med 1999; 159: 1527-1532.

33 Ievers-Landis CE, Redline S. Pediatric sleep apnea: implications of the epidemic of childhood overweight. Am J Respir Crit Care Med 2007; 175: 436-441.

34 Carotenuto M, Bruni O, Santoro N, Del Giudice EM, Perrone L, Pascotto A. Waist circumference predicts the occurrence of sleep-disordered breathing in obese children and adolescents: a questionnaire-based study. Sleep Med 2006; 7: 357-361.

35 Li AM, Chan MH, Chan DF, et al. Insulin and obstructive sleep apnea in obese Chinese children. Pediatr Pulmonol 2006; 41: 1175-1181.

36 De Portugal Alvarez J, De Portugal F, et al. Indice cintura/ cadera y factores de riesgo vascular en sujetos obesos y no obesos. [Waist-to-hip ratio and vascular risk factors in obese and non-obese subjects.] An Med Intern (Madrid) 1997; 14: 13-20.

37 Moreno LA, Pineda I, Rodríguez G, Fleta J, Sarría A, Bueno M. Waist circumference for the screening of the metabolic syndrome in children. Acta Paediatr 2002; 91: 1307-1312.

38 Gozal D, Pope DW. Snoring during early childhood and academic performance at ages thirteen to fourteen years. Pediatrics 2001; 107: 1394-1399.

39 Ali NJ, Pitson DJ, Stradling JR. Snoring, sleep disturbance and behavior in 4-5 year olds. Arch Dis Child 1993; 68: 360-366.

40 Nixon GM, Brouillette RT. Paediatric obstructive sleep apnoea. Thorax 2005; 60: 511-516.

41 Marcus CL, Omlin KJ, Basinki DJ, et al. Normal polysomnographic values for children and adolescents. Am Rev Respir Dis 1992; 146: 1235-1239.

42 Acebo C, Millman RP, Rosenberg C, Cavallo A, Carskadon MA. Sleep, breathing, and cephalometrics in older children and young adults. Part I - Normative values. Chest 1996; 109: 664-672.

43 Uliel S, Tauman R, Greenfeld M, Sivan Y. Normal polysomnographic respiratory values in children and adolescents. Chest 2004; 125: 872-878.

44 Traeger N, Schultz B, Pollock AN, Mason T, Marcus CL, Arens R. Polysomnographic values in children 2-9 years old: additional data and review of the literature. Pediatr Pulmonol 2005; 40: 22-30.

45 Pepin JL, Delavie N, Pin I, et al. Pulse transit time improves detection of sleep respiratory events and microarousals in children. Chest 2005; 127: 722-730. 